\title{
Mastery of glove use in nursing practice at the Hassan II University Teaching Hospital of Fes- Morocco
}

\author{
Moussa Benboubker ${ }^{1}$, Aziz Nhilii ${ }^{1}$, Tarik Sadki², Boujamaa El Marnissi ${ }^{3}$ \\ ${ }^{1}$ Medical and Nursing Department, Hassan II University Teaching Hospital of Fes- Morocco \\ ${ }^{2}$ Audit and Management Control Department, \\ Hassan II University Teaching Hospital of Fes- Morocco \\ ${ }^{3}$ Development and Research Department, Hassan II University Teaching Hospital of Fes- Morocco
}

\begin{abstract}
Gloves are worn to protect from contamination by microorganisms; this measure is intended to protect the hands of health care workers and to minimize the risk of transmission of infectious agents to patients. This survey aims to assess knowledge, attitudes, and practices concerning the use of disposable gloves among the nursing staff of the Hassan II University Hospital in Fes. This is a prospective and evaluative cross-sectional study covering two months. Data were collected using an anonymous, self-administered questionnaire. The population studied was quite young, 76.5 percent of them being between 20 and 30 years of age. Results showed that 264 (85.99\%) of the participants had received training in disposable glove mastery. Moreover, 161 (52.3\%) of the participants reported always changing disposable gloves from one patient to another. In contrast, 231 (75.2\%) emphasized the need to change gloves every time they came into contact with blood or other body fluids. However, studies using self-administered questionnaires, as in our survey, provide information about self-reported claims and are not always related to practical implications. Inappropriate use of gloves was frequently reported in this study. This survey showed a misconception of risk in various practice situations, with some results of over-use of gloves reflecting this engendered sense of personal protection.
\end{abstract}

Keywords: personal protective equipment; infectious disease transmission; knowledge; attitudes; nurses; Morocco

\section{Corresponding author:}

Moussa Benboubker

Medical and Nursing Department, Hassan II University Teaching Hospital of Fes- Morocco

Email: benboubker.chh2@gmail.com 


\section{Introduction:}

The emergence of infections in the 1980s, like human immunodeficiency virus and hepatitis virus, led to the drafting of "universal precautions", ${ }^{1}$ which have then extended to the "standard precautions", published by the Centers for Diseases Control and Prevention in Atlanta in 1996. ${ }^{2}$ These precautions recommended the use of gloves in the event of exposure to biological fluids and contact with mucous membranes; this measure tries to isolate the hands of healthcare workers to ensure better protection, ${ }^{3}$ and it also makes it possible to ensure the hygiene of the hands after the use of gloves, to minimize the risk of transmission of infectious agents to patients. ${ }^{4}$ The suitable use of gloves is essential to patient care practice to prevent the transmission of infections and to protect the healthcare workers and patients against infectious risks. ${ }^{5}$ These recommendations are not easy to apply in the health care environment for several reasons, in particular, the mastery of using suitable single-use gloves. ${ }^{6,7}$ Despite their justified interest and contribution to improving the quality of care, the practice of wearing disposable gloves remains suboptimal and less respected in cases of risk of contact with blood during technical procedures. . $^{8,9,13}$ Its implementation, however, requires that the indications and practical modalities are defined and that staff are well trained and aware of the interest and the necessity for wearing gloves in the care setting. This approach can succeed only if there is valid information on the level of knowledge and the attitudes of carers towards this practice.

At the HASSAN II University Teaching Hospital of Fes, few actions have so far been taken on this issue. We thus proposed to initiate an investigation aiming at the assessment of knowledge and the practical attitudes of nurses regarding the use of the disposable gloves and to deduce actions from them to be implemented to enhance the safety of care.

\section{Methods}

\section{Population}

This is a sample survey with a cross-sectional design, performed during May 2013, which focused on the five-hospital training under the HASSAN II University Teaching Hospital of Fes. All nurses were eligible to participate in this survey; the population included the specialized graduate registered nurse (RN), the polyvalent graduate registered nurse (MDN), and caregivers in various disciplines and units.

\section{Survey methods}

The survey data were collected through an anonymous self-administered questionnaire, developed by the Healthcare-Associated Infections Control Committee (HAlsCC) of the HASSAN II University Teaching Hospital of Fes. The questionnaire was developed based on the literature database and was validated by the HAlsCC referents. It relates in the first part to the characteristics of the studied population (age, profile, sex, hospital, department, and the sector of clinical activity). A second part relates to the level of knowledge and attitudes. It addresses three distinct items (mastery of wearing gloves in general situations, mastery of wearing gloves in particular situations, mastery of wearing gloves in risk situations), each item comprising an attitudinal scale: never, sometimes, often and always.

The practices were regarded as being compliant, when the item "always" was checked; limited, when the item "often" was checked; and noncompliant when "sometimes" or "never" were selected.

This survey was conducted among all the nurses practicing in the HASSAN II University Teaching Hospital of Fes, to ensure that each of these groups was adequately represented. The sampling frame was been developed from the database in the same year by the Human Resources Department and Cooperation (HRDC), made of 1158 nurses on the whole. Nurses employed by associations were not included in the study.

The questionnaires were drawn up and circulated to all the clinical departments in May 2013 on one day according to a pre-established agenda. Ten investigators were recruited and trained in the principles and purpose of the survey and how to fill out the questionnaire to explain to the participants. The questionnaire was distributed at the beginning of the study with a random sample to validate the methodology and the monitoring tools required for this survey, ensure that the questions are well understood, check the quality of the responses, 
and estimate the processing time. Informed consent was obtained after explaining the purpose of the survey to participants.

\section{Statistical analysis}

Data collection and analysis were conducted using Epi Info 7 software (Centers for Disease Control and Prevention, Atlanta, GA). The analysis included the socio-demographic and professional data, as well as the knowledge, attitudes, and practices towards the mastery of single-use gloves in the recommended situations. The chi-squared test was used to compare all the variables and the significance threshold was fixed ( $p$ value) at 0.05 .

\section{Results}

Sociodemographic and professional characteristics

With 578 participants eligible to participate, the survey involved 307 nurses (53.8\%). The nursing professions are represented in three distinct categories, with a relatively high rate of $73.2 \%(90 / 123)$ for Registered Nurse Specialists (RNs) compared to 51.2\% (154/301) for Registered Polyvalent Nurses (RNs) and 40.9\% (63/154) for Caregivers. The population studied was quite young with $76.5 \%$ (235/307) aged between 20-30 years, and the sex-ratio was 1.03. Almost half $(45.6 \%, 140 / 307)$ of the participants worked in the surgical sector (Table I).

\section{Training and education}

Two hundred sixty-four participants (86\%) claimed that they had received training on the mastery and the use of single-use gloves, 162 in the previous five years. Nurses claiming to be the most trained are the specialized graduate registered nurse (RN) $95.6 \%(86 / 90)$ followed by the polyvalent graduate registered nurse (MDN) 92.2\% (142/154) and caregivers' $57.1 \%$ (36/63) (Table I).

\section{The use of disposable gloves in basic nursing practice} Of the survey respondents, $52.3 \%(161 / 307)$ cited the change of single-use gloves "always" between two patients as an essential measure to prevent crosstransmission and accidents with blood exposure, while only $3.1 \%$ (10/307) declared that they do not remove the single-use gloves in the same situations. Similarly, change of the gloves is not systematic between two activities, with only $38.2 \%(118 / 307)$ of the

Table I. Sociodemographic and professional characteristics of the study population

\begin{tabular}{|c|c|c|c|}
\hline & & $\begin{array}{l}\text { Nurses }(n=307) \\
n(\%)\end{array}$ & Pvalue \\
\hline \multirow{4}{*}{ Age (years) } & $20-30$ & $235(76.5)$ & 0.001 \\
\hline & $31-40$ & 35 (11.4) & \\
\hline & $41-50$ & $28(9.1)$ & \\
\hline & $51-60$ & $09(2.9)$ & \\
\hline \multirow{3}{*}{ Sex } & Sex-ratio & $120 / 117(1.03)$ & \multirow{3}{*}{0.001} \\
\hline & Female & $117(38.1)$ & \\
\hline & Male & $120(62.0)$ & \\
\hline \multirow{3}{*}{ Professional category } & Polyvalent nurse (MDN) & $154(51.2)$ & \multirow{3}{*}{0.001} \\
\hline & Specialized nurse (RN) & $90(73.2)$ & \\
\hline & Caregivers & $63(40.9)$ & \\
\hline \multirow{2}{*}{ Training } & Trained & $264(86.0)$ & \multirow{2}{*}{-0.001} \\
\hline & Trained $\leq 5$ years & $166(54.1)$ & \\
\hline \multirow{3}{*}{ Sector activity } & Medical & $60(19.5)$ & \multirow{3}{*}{0.001} \\
\hline & Surgical & $140(45.6)$ & \\
\hline & Medical-techniques & $107(34.9)$ & \\
\hline
\end{tabular}


respondents "always" changing gloves and 4.9\% $(16 / 307)$ stating that they do not change gloves. Overall $51 \%$ did not satisfy the mastery of single-use gloves between two activities according to the WHO recommendations ${ }^{10}$ (never: 16/307, sometimes: 72/307, often: 71/307) (Table II).

\section{The use of disposable gloves in particular nursing practice}

On the one hand, $56.3 \%$ (173/307) of participants change gloves during the daily personal hygiene of a patient. On the other hand, $0.3 \%(1 / 307)$ do not change gloves at the same provision. Of the 307 participants, 31 did not respond systematically. During IV/IM injection or blood taking samples, between $23.2 \%$ and $37.3 \%$ of the participants confirm the change of single-use gloves designed for this purpose. Regarding the draining of urine collectors,
$57.2 \%(176 / 307)$ of the nurses state that they always wear single-use gloves, $11.9 \%$ (37/307) do not do it systematically, and $0.3 \%$ never wear gloves in this situation (Table III). Finally, 56.3\% (173/307) respect the recommendations to wear single-use gloves during the removal of a contaminated dressing.

\section{The use of disposable gloves in high-risk nursing practice}

Two hundred and thirty-one participants (75.2\%) abide by the recommendations for mastering of disposable gloves in case of blood or body fluid contact risk. Equally, 64.5\% (198/307) reported wearing single-use gloves when there is a risk of contact with mucous membranes, and few respondents said that they do not. In case of risk of contact with the injured skin of the patient or during basic patient care, $61.5 \%$ $(189 / 307)$ of the participants stated they complied

Table II. The use of disposable gloves in basic nursing practice

\begin{tabular}{|c|c|c|c|c|c|}
\hline & \multicolumn{5}{|c|}{ Responses $(n=307)$} \\
\hline & $\begin{array}{l}\text { Never } \\
n(\%)\end{array}$ & $\begin{array}{l}\text { Sometimes } \\
n(\%)\end{array}$ & $\begin{array}{l}\text { Often } \\
n(\%)\end{array}$ & $\begin{array}{l}\text { Always } \\
n \text { (\%) }\end{array}$ & Pvalue \\
\hline \multicolumn{6}{|c|}{ Change of disposable gloves declared: } \\
\hline Between two patients & $10(3.1)$ & $43(13.8)$ & $53(17.7)$ & $161(52.3)$ & 0.22 \\
\hline Between two activities & $16(4.9)$ & $72(23.2)$ & $71(22.9)$ & $118(38.2)$ & 0.82 \\
\hline
\end{tabular}

Table III. The use of disposable gloves in particular nursing practice

\begin{tabular}{llllll} 
& \multicolumn{2}{l}{ Responses $(\mathrm{n}=307)$} \\
& $\begin{array}{l}\text { Never } \\
n(\%)\end{array}$ & $\begin{array}{l}\text { Sometimes } \\
n(\%)\end{array}$ & $\begin{array}{l}\text { Often } \\
n(\%)\end{array}$ & $\begin{array}{l}\text { Always } \\
n(\%)\end{array}$ & Pvalue \\
\hline $\begin{array}{l}\text { In specific situations, nurses wear } \\
\text { disposable gloves when they: }\end{array}$ & & & & & \\
$\begin{array}{l}\text { Perform personal hygiene of a patient } \\
\text { Remove drains }\end{array}$ & $1(0.3)$ & $11(3.4)$ & $20(6.4)$ & $173(56.3)$ & 0.56 \\
\hline Empty urine collectors & $2(0.6)$ & $14(4.3)$ & $20(6.4)$ & $172(56.0)$ & 0.56 \\
\hline Remove of a contaminated dressing & $1(0.3)$ & $15(4.6)$ & $23(7.3)$ & $176(57.2)$ & 0.56 \\
\hline Administer an IM / IV injection & $2(0.6)$ & $19(6.1)$ & $37(11.9)$ & $173(56.3)$ & 0.56 \\
\hline Insert a peripheral venous catheter & $48(15.6)$ & $69(22.3)$ & $38(12.2)$ & $72(23.2)$ & 0.70 \\
\hline Take a venous blood sample & $11(3.4)$ & $81(26.3)$ & $41(13.1)$ & $109(35.5)$ & 0.67 \\
\hline Handle waste & $8(2.4)$ & $70(22.6)$ & $49(15.9)$ & $115(37.3)$ & 0.66 \\
\hline
\end{tabular}


with this practice. For other situations, in the case of contaminated material manipulation, contaminated laundry or biological samples, between $51.1 \%$ and $69.4 \%$ reported wearing disposable gloves. Similarly, and when it comes to protecting oneself when their hands have injuries, $69.1 \%$ of respondents $(213 / 307)$ reported using single-use gloves in this situation (Table IV). In total, 197 out of 307 (64.08\%) comply with all recommendations relating to the mastery of single-use gloves for all risk situations.

\section{Discussion}

The study focused on "practical knowledge and attitudes" regarding the use of single-use gloves. The results showed poor control of glove-wearing in certain situations (during insertion of a peripheral venous catheter, when taking blood samples, when performing IV/IM injection and between activities), as recommended. Self-administered questionnaire studies, such as our survey, provide information on self-reported claims and are notal ways associated with practical implications. ${ }^{11}$ However, this would enable and facilitate providing an improvement plan that addresses potential barriers to the accomplishment and adherence to best practices for single-use glove recommendations.

Our data show that $86.0 \%$ of participants stated that they have been trained about the mastery of single- use gloves practice in a health care setting, 54.1\% of them during the past five years. Several studies have shown the contribution of initial training on the knowledge of caregivers. In France, an audit of universal precautions among 4439 professionals showed that initial training had a greater impact on practice and caregivers' knowledge than continuing education. ${ }^{12}$ Our results confirm this hypothesis. Indeed, the relatively acceptable rates lead us to assume that the attitudes reported are the result of the training programmes received as part of their initial training, since a high rate of participants are newly recruited in the hospital centre mentioned.

Change of gloves between two activities or between two patients was reported to be lower than that of wearing gloves in the blood contact situation. These results are relatively consistent with those found in a study conducted among local health staff of the Souss-Massa-Drâa region in the south of Morocco, which reports a rate of $90 \%$ of wearing gloves during contact with body fluids. ${ }^{13}$ Another study has shown that the use of gloves is appropriate for situations where contact with body fluids is envisaged or when the patients are to be managed with precautions, as situations influencing workers' decisions regarding the wearing of disposable gloves. ${ }^{14,15}$ Similarly, a study conducted at the Samar Public University in the Philippines showed that $94.8 \%$ of staff wear gloves

Table IV. The use of disposable gloves in high-risk nursing practice

\begin{tabular}{rrrrr} 
Responses $(n=307)$ & & & \\
Never & Sometimes & Often & Always & Pvalue \\
$n(\%)$ & $n(\%)$ & $n(\%)$ & $n(\%)$ & \\
\hline
\end{tabular}

\section{Professionals wear disposable gloves when}

they:

Will be in contact with blood or other body fluid $\quad 2(0.65) \quad 18(5.80) \quad 43(14.1) \quad 231 \quad 0.14$

\begin{tabular}{lrrrrr}
\hline Will be in contact with mucous membranes & $4(1.2)$ & $20(6.4)$ & $57(18.7)$ & $58(64.5)$ & 0.47 \\
\hline Will be in contact with patient's injured skin & $5(1.5)$ & $32(10.4)$ & $56(18.3)$ & $57(61.5)$ & 0.52 \\
\hline Handle biological samples & $4(1.2)$ & $52(16.8)$ & $51(16.5)$ & $51(51.1)$ & 0.59 \\
\hline Handle contaminated laundry & $4(1.2)$ & $23(7.3)$ & $55(18.0)$ & $56(57.8)$ & 0.56 \\
\hline Handle contaminated material & $3(0.9)$ & $19(6.1)$ & $49(15.9)$ & $49(69.4)$ & 0.23 \\
\hline Have skin lesions when providing care & $2(0.6)$ & $16(5.2)$ & $45(14.7)$ & $46(69.1)$ & 0.23
\end{tabular}


when there is a blood contact risk. ${ }^{16}$ At the Givors Hospital Center, the high frequency declared of gloves worn by nurses was for venous samples practice. ${ }^{17}$

Concerning the appropriate use of single-use gloves when providing personal hygiene, the reported mastery of gloves ranged from $43.7 \%$ to $56.3 \%$. These results are far from those revealed by a survey in Belgium showing that $18 \%$ of nurses do not wear gloves during genital care. ${ }^{18}$ The results declared in our study can be explained by the fact that this practice is allocated solely to caregivers.

Unlike the results obtained in personal hygiene situations, the reports of mastering gloves during venous manipulations have been poor in several situations (performing an IM / SC injection, placing a venous line and performing a blood sample). Although all categories of nurses at the centre are concerned with these acts, the reported rates were between $23.2 \%$ and $37.3 \%$. In response to these concerns, the mastering of gloves was not systematic, unlike other studies that revealed that the indications for wearing single-use gloves were almost always respected when performing a venous puncture. ${ }^{18}$ These results lead us to suppose that most nurses have developed the attitude of working without gloves or with bare hands when manipulating venous lines or performing phlebotomy.

The noncompliance with glove use in some situations reported in this study may be related to the risk misperception. However, some good results of wearing gloves reflect this notion of individual protection engendered. This is confirmed by observation audits carried out in France, where the gloves were removed after bed arrangement in only $60 \%$ of cases, and in $61.1 \%$ of cases, they were removed after personal hygiene practice. ${ }^{18,19}$ Other studies confirm this suboptimal behaviour or the misuse of gloves when that is not recommended, to protect themselves, or to place one more barriers during care practices. ${ }^{20,21,22}$

One of the main limitations of this study is related to our methods. Self-declarations make it possible to assess the knowledge more than professional practice, and this does not reflect at any time the actual behaviour of the participants. ${ }^{23}$ On several issues, professionals probably responded to situations they have never encountered, and in other cases, several professionals responded to questions about practice which do not concern them a priori on account their profile or work occupation. Similarly, it should be noted that the objectivity of responses to a self-questionnaire can still be discussed, and selfevaluation as an approach may lead to a response bias. ${ }^{24,25}$ The results were particularly good in certain situations: is it the reported practices, or a tendency of participants to show perhaps wrongly their good knowledge towards using disposable gloves?

The results of this study show that the knowledge of the nurses towards mastering gloves was still unsatisfactory. A multimodal strategy is a key point to enhance nurses' attitudes and knowledge, which include specific training, implementing recommendations to the work environment, and assessing practices according to a regular schedule. ${ }^{26,27}$

\section{Declaration of conflicting interests}

The author(s) declared no potential conflicts of interest with respect to the research, authorship, and/ or publication of this article.

\section{Funding}

This work was supported by the University teaching Hospital HASSAN II of Fes, Morocco

\section{Acknowledgements}

We would like to thank Mustapha Mahmoud, the president of the HAlsCC, and Said Latrache, the director of the HRDC department of HASSAN II University Hospital in Fes, Morocco, for his advice in planning and designing the analysis part of the project. We also thank the volunteers who participated in this project

\section{Ethical approval}

This survey was approved by the Ethics Committee of the Faculty of Medicine and Pharmacy and the University Hospital Center of Fes of Morocco. 


\section{References:}

1. Centers for Disease Control and Prevention (CDC). Guidelines for universal precautions: Recommendations for prevention of HIV transmission in health-care settings, August 21, 1987. https://www.cdc.gov/mmwr/preview/ mmwrhtml/00023587.htm [Accessed May 4, 2014]

2. Siegel JD, Rhinehart E, Jackson M, Chiarello $L$, and the Healthcare Infection Control Practices Advisory Committee 2007. Guideline for Isolation Precautions: Preventing Transmission of Infectious Agents in Healthcare Settings June 2007. Public Health Service, US Department of Health and Human Services, Centers for Disease Control and Prevention, Atlanta Georgia. https://www.cdc.gov/infectioncontrol/ guidelines/isolation/index.html [Accessed May 4, 2014]

3. Ministry of Employment and Solidarity French Republic. Circular DGS/DH/98/249 on the prevention of transmission of infectious agents carried by blood or biological fluids during care in health care institutions, April 1998. https:// bdoc.ofdt.fr/index.php?lvl=notice_display\&id=684 [Accessed May 4, 2014]

4. Pittet D, Boyce JM. Revolutionising hand hygiene in healthcare settings: guidelines revisited. Lancet Infect Dis 2003; 3(5): 269-270. https://doi.org/10.1016/s1473-3099(03)00601-7

5. Girou E, Chevaliez S, Challine D, et al. Determinant roles of environmental contamination and noncompliance with standard precautions in the risk of hepatitis $\mathrm{C}$ virus transmission in a haemodialysis unit. Clin Infect Dis 2008; 47(5): 627-633. https://doi.org/10.1086/590564

6. Ministry of Employment and Solidarity-DGS/DH and the High Council of Public Health. Controlling the distribution of BMR imported into France by repatriated patients or patients with a history of hospitalization abroad in France, Collection of Avis and Reports, November 2010. https://www.hcsp.fr/ explore.cgi/avisrapportsdomaine?clefr=201 [Accessed May 4, 2014]

7. Clock SA, Cohen B, Behta M, Ross B, Larson EL. Contact precautions for multidrug-resistant organisms: Current recommendations and actual practice. Am J Infect Control 2010; 38(2): 105-111. https://doi.org/10.1016/j. ajic.2009.08.008

8. Weber A. Audit multicentrique sur les pratiques du port de gants à usage unique non stériles dans les unités de soins. Hygiènes 2001; 11: 339-345.

9. Thompson BL, Dwyer DM, Ussery XT, Denman S, Vacek P, Schwartz B. Handwashing and glove use in a long-termcare facility. Infect Control Hosp Epidemiol 1997; 18(2): 97103. https://doi/abs/10.1086/647562

10. World Health Organization (WHO). Guidelines on hand hygiene in health care: first global patient safety challenge clean care is safer care, 2009. https://www.who.int/ gpsc/5may/tools/9789241597906/en/ [Accessed May 4, 2014].

11. BinardF. The knowledge, attitudes and practices questionnaire as a tool for assessing professional practices: about a survey of blood exposure incidents in a healthcare facility. Hygiènes 2006; XIV(5): 326-334.

12. Kadi Z. Knowledge audit on standard precautions in healthcare institutions in the Picardie region, French. Regional report, 2011 (ARLIN Picardie/DOC/74).
13. Mbarki A. Prevalence of blood exposure accidents among healthcare workers in the Souss-Massa-Drâa region, Morocco. Science Lib Editions Mersenne 2013, Volume 5, N 130111, ISSN 2111-4706.

14. Fuller C, Savage J, Besser S, et al. The dirty hand in the latex glove. A study of hand hygiene compliance when gloves are worn. Infect Control Hosp Epidemiol 2011; 32(12): 1194-1199. https://doi.org/10.1086/662619

15. Wilson J, Lynam S, Singleton J, Loveday H. O003: The misuse of clinical gloves: risk of cross-infection and factors influencing the decision of healthcare workers to wear gloves. Antimicrob Resist Infect Control 2013; 2. https://doi. org/10.1186/2047-2994-2-S1-O3

16. Leodoro J. Knowledge of and compliance with standard precautions among student nurses. International Journal of Advanced Nursing Studies 2012; 1(2): 84-97.

17. Thiriet $L$. Evaluation of care glove use practices during nursing acts. Hygiènes 2011; XIX(5): 285-291.

18. De Wandel D, Vogler's D, Blot S. The WHO glove use pyramid: knowledge gaps among Belgian nurses. BMC Proceedings 2011; 5(6): P114. https://doi.org/10.1186/1753-6561-5S6-P114

19. Reboux S. Dependent patient toilet: how standard hygiene precautions are applied. Hygiènes 2008; XVI(2): 143-148.

20. Wilson J, Prieto J, Singleton J, O'Connor V, Lynam S, Loveday $H$. The misuse and overuse of non-sterile gloves: application of an audit tool to define the problem. J Infect Prev 2015; 16(1): 24-31. https://doi.org/10.1177/1757177414558673

21. Picheansanthian W, Chotibang J. Glove utilization in the prevention of cross transmission: a systematic review. JBI Database of Systematic Reviews and Implementation Reports 2015; 13(4): 188-230. https://doi.org/10.11124/ jbisrir-2015-1817

22. Gon G, de Bruin M, de Barra M, et al. Hands washing, glove use, and avoiding recontamination before aseptic procedures at birth: A multicenter time-and-motion study conducted in Zanzibar. Am J Infect Control 2019; 47(2): 149-156. https:// doi.org/10.1016/j.ajic.2018.07.021

23. Madan AK, Raafat A, Hunt JP, Rentz D, Wahle MJ, Flint LM. Barrier precautions in trauma: is knowledge enough. J Trauma 2002; 52(3): 540-543. https://doi.org/10.1097/00005373200203000-00020

24. Monier S, Garcia EL, Giard M, et al. Programme stoprisk: all about standard precautions. BMC Proc 2011; 5(6): P283. https://doi.org/10.1186/1753-6561-5-S6-P283

25. Mallaret MR. Resources and organization of 124 facilities in the Southeast inter-region for the implementation of standard precautions and septic isolation. Med Mal Infect 2004; 34(10): 477-484.

26. Pittet D, Hugonnet S, Harbarth S, et al. Effectiveness of a hospital-wide programme to improve compliance with hand hygiene. Lancet 2000; 356(9238): 1307-1312. https://doi. org/10.1016/s0140-6736(00)02814-2

27. Atif ML, Sadaoui F, Bezzaoucha A, et al. Reduction of nosocomial pneumonia using surveillance and targeted interventions in an Algerian neonatal intensive care unit. Infect Control Hosp Epidemiol 2009; 30(7): 712-713. https://doi.org/10.1086/598337 